\title{
A HPLC-MS/MS METHOD DEVELOPMENT AND VALIDATION FOR THE SIMULTANEOUS DETERMINATION OF BISOPROLOL AND ENALAPRIL IN THE PRESENT OF ENALAPRILAT IN HUMAN PLASMA
}

\section{LILIYA LOGOYDA ${ }^{*}$, DMYTRO KOROBKOํ, OLEKSANDRA OLESHCHUK ${ }^{2}$, TARAS PRONIV ${ }^{3}$, MARIYA DMUTRIV ${ }^{3}$}

${ }^{1}$ Pharmaceutical Chemistry Department, Pharmaceutical Faculty, I. Horbachevsky Ternopil State Medical University, Ternopil City, Ukraine, ${ }^{2}$ Pharmacology and Clinical Pharmacology Department, I. Horbachevsky Ternopil State Medical University, Ternopil City, Ukraine, ${ }^{3}$ State Service on Medicinal Products and Drugs Control in Ternopil Region, Ternopil City, Ukraine Email: logojda@tdmu.edu.ua

Received: 18 Oct 2017, Revised and Accepted: 09 Jan 2018

\section{ABSTRACT}

Objective: A highly specific, sensitive and rapid HPLC-MS/MS method has been developed and validated for the simultaneous quantification of bisoprolol and enalapril in the present of enalaprilat in human plasma.

Methods: Analytes were extracted from plasma using a protein precipitation extraction method. Chromatography was achieved on Discovery C18, $50 \times 2.1 \mathrm{~mm}, 5 \mu \mathrm{m}$ column. Samples were chromatographed in a gradient mode (eluent A (acetonitrile-water-formic acid, 5: 95 : $0.1 \mathrm{v} / \mathrm{v}$ ), eluent B (acetonitrile-formic acid, 100: $0.1 \mathrm{v} / \mathrm{v}$ )). The initial content of the eluent B is $0 \%$, which increases linearly by 1.0 min to $100 \%$ and to 1.01 min returns to the initial $0 \%$. The mobile phase was delivered at a flow rate of $0.400 \mathrm{ml} / \mathrm{min}$ into the mass spectrometer ESI chamber. The sample volume was $5 \mu \mathrm{l}$.

Results: The total chromatographic run time was $2.0 \mathrm{~min}$ and the elution of bisoprolol, enalapril, enalaprilat and IS (verapamil) occurred at $~ 1.01$, 1.03, 0.96 and $1.09 \mathrm{~min}$, respectively. A linear response function was established at $0.5-50 \mathrm{ng} / \mathrm{ml}$ for bisoprolol fumarate, 2-200 ng/ml for enalapril maleate, $1-100 \mathrm{ng} / \mathrm{ml}$ for enalaprilat dehydrate in human plasma. The intraday and interday accuracy and precisions were in the range of $0.311 \%$ $0.647 \%$ and $0.364 \%-0.572 \%$ for bisoprolol, $0.321 \%-0.747 \%$ and $0.390 \%-0.673 \%$ for enalapril, $0.221 \%-0.547 \%$ and $0.264 \%-0.773 \%$ for enalaprilat, respectively.

Conclusion: A new rapid method was developed for simultaneous determination of bisoprolol and enalapril in the present of enalaprilat in human plasma. The method was strictly validated according to the ICH guidelines. The information thus obtained from the study can be used for the full pharmacokinetic profiling in individuals.

Keywords: Bisoprolol, Enalapril, Enalaprilat, HPLC-MS/MS, Validation, Human plasma

(C) 2018 The Authors. Published by Innovare Academic Sciences Pvt Ltd. This is an open access article under the CC BY license (http://creativecommons.org/licenses/by/4.0/) DOI: http://dx.doi.org/10.22159/ijap.2018v10i2.23195

\section{INTRODUCTION}

Bisoprolol is a synthetic, $\beta 1$-selective (cardioselective) adrenoceptor blocking agent without significant membrane stabilizing activity or intrinsic sympathomimetic activity in its therapeutic dosage range. The chemical name of bisoprolol fumarate is $1-\{4-[(2-$ isopropoxyethoxy) methyl] phenoxy\}-3-(isopropyl amino) propan2-ol (fig. 1) [1].

Enalapril maleate is chemically described as (2S)-1-[(2S)-2-[[(1S)-1(Ethoxycarbonyl)-3-phenylpropyl] amino] propanoyl] pyrrolidine-2carboxylic acid (Z)-butenedioate (fig. 2). Enalapril maleate is a prodrug which metabolized rapidly in the liver to ethyl ester of a long-acting enalaprilat (fig. 3) which inhibits angiotensin-converting enzyme (ACE) in human subjects and animals [2].<smiles>O=C(O)/C=C/C(=O)O</smiles>

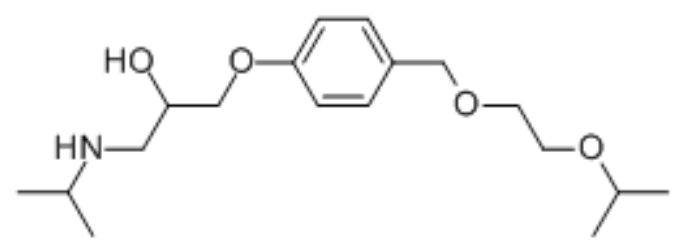

Fig. 1: Chemical structure of bisoprolol fumarate

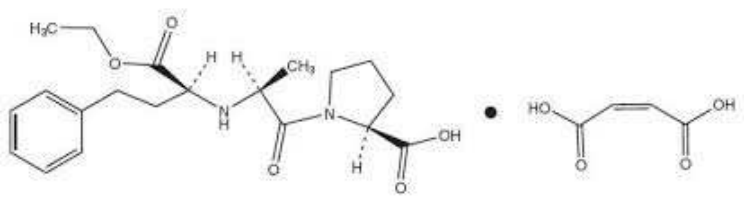

Fig. 2: Chemical structure of enalapril maleate

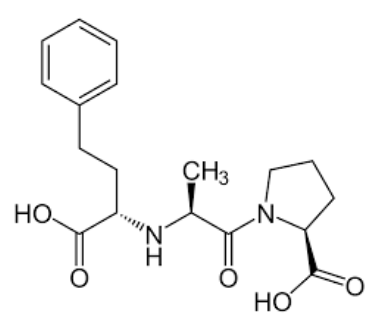

Fig. 2: Chemical structure of enalaprilat 
reported the determination of bisoprolol in human plasma by an LC-ESIMS method. Plasma aliquots were processed using solid phase extraction methodology. Chromatographic separation of bisoprolol was achieved on BetaBasic 8 column using an isocratic elution. The linearity range was $0.5-70 \mathrm{ng} / \mathrm{ml}$ for bisoprolol in plasma [4]. Recently, Liu et al. reported a liquid chromatography-tandem mass spectrometric (LC-MS/MS) method for the quantitation of bisoprolol in human plasma with a linearity range of $0.5-100 \mathrm{ng} / \mathrm{ml}$. Plasma aliquots spiked with bisoprolol were processed using simple protein precipitation extraction method [5] followed by chromatographic separation of bisoprolol achieved on Capcell Pak C18 MG III column $(100 \mathrm{~mm} \times 2.0 \mathrm{~mm}, 5 \mu)$, using gradient elution. Similarly, Hemavanthi G. et al. reported an LC-electrospray ionization (ESI)-MS for determination of bisoprolol and triamterene in human plasma. Chromatographic separation of bisoprolol was achieved on Welchrom XB C18, $50 \times 4.6 \mathrm{~mm} 0,5 \mu \mathrm{m}$ column using an isocratic mobile phase $(2 \mathrm{mmol}$ ammonium formate: acetonitrile, $70: 30 \mathrm{v} / \mathrm{v})$ at a flow rate of $0.60 \mathrm{ml} / \mathrm{min}$. A linear response function was established at $2.04-210 \mathrm{ng} / \mathrm{ml}$ for both the analytes in human plasma. Total run time for this analysis was $3.5 \mathrm{~min}$ [6].

Bisoprolol fumarate can be determined by various methods such as ultraviolet, reverse phase high-performance LC (HPLC), LC-MS/MS, and high-performance thin-layer chromatography. Methods have been reported for analysis of bisoprolol fumarate in mono-or in combination with other drugs in pharmaceutical formulations [7-11]. From the literature survey, it is very clear that no method has been reported for simultaneous determination of bisoprolol and enalapril in the present of enalaprilat in human plasma by LC-MS/MS. As for quantification, LCMS/MS seems to be more sensitive and precise for the simultaneous determination of bisoprolol and enalapril in the present of enalaprilat in human plasma. The proposed method is validated as per guidelines [12].

\section{MATERIALS AND METHODS}

\section{Chemicals and reagents}

Bisoprolol (purity $100.0 \%$ ), enalapril (purity $99.3 \%$ ), enalaprilat (purity $100.0 \%$ ), verapamil (Internal Standard) (purity $99.9 \%$ ) were purchased from Moehs Catalana, S. L., Spain, Zhejiang Huahai Pharmaceutical Co., Ltd, KHP, EDQM-Council of Europe. HPLC grade acetonitrile and methanol were purchased from CHROMASOLV, HPLC grade formic acid was purchased from Fluka. All other chemicals and reagents were of analytical grade. Microcaps ${ }^{\circledR}$ disposable micropipettes (50 $\mu \mathrm{l}$, catalog number: 1-000-0500) were purchased from Drummond Scientific Company, USA. The control human dipotassium ethylenediaminetetraacetic acid (K2EDTA) plasma sample was procured from Red Cross Society, Ukraine.

\section{Instrumentation and chromatographic conditions}

A Shimadzu HT (Shimadzu, Japan) LC system equipped with degasser (DGU-14A), binary pump (LC-20ADXR) along with autosampler (SIL-20ACXR) was used to inject $5 \mu$ aliquots of the processed samples on Discovery C18, $50 \times 2.1 \mathrm{~mm}, 5 \mu \mathrm{m}$ column maintained at $25 \pm 1{ }^{\circ} \mathrm{C}$. Samples were chromatographed in a gradient mode (eluent A (acetonitrile-water-formic acid, 5: 95: $0.1 \mathrm{v} / \mathrm{v}$ ), eluent B (acetonitrile-formic acid, 100: $0.1 \mathrm{v} / \mathrm{v}$ )). The initial content of the eluent $\mathrm{B}$ is $0 \%$, which increases linearly by $1.0 \mathrm{~min}$ to $100 \%$ and to $1.01 \mathrm{~min}$ returns to the initial $0 \%$. The mobile phase was delivered at a flow rate of $0.400 \mathrm{ml} / \mathrm{min}$ into the mass spectrometer ESI chamber. Parameters of electrospray ionizer and MRM parameters are listed in table 1-2. The analytical data were processed by analyst software (version 1.5.2).

Table 1: Parameters of ionizer electrospray

\begin{tabular}{lll}
\hline & Parametr & Value \\
\hline 1 & Polarity & Positive \\
2 & Nebulizer Gas (NEB, Gas 1) & 15 \\
3 & Curtain Gas (CUR) & 8 \\
4 & Collision Gas (CAD) & 4 \\
5 & IonSpray Voltage (IS) & 5000 \\
6 & Temperature (TEM) & 400 \\
7 & Turbo IonSpray Gas & 8 \\
8 & Horizontal Position & 5.3 \\
9 & Lateral Position & 1.3 \\
\hline
\end{tabular}

Table 2: Multiple reaction monitoring (MRM) parameters

\begin{tabular}{|c|c|c|c|c|c|c|c|c|}
\hline ID & Parent, $\mathbf{m} / \mathbf{z}$ & Daughter, $\mathbf{m} / \mathbf{z}$ & Time, ms & DP, V & FP, V & EP, V & $\mathrm{CE}, \mathrm{V}$ & CXP, V \\
\hline Enalapril & 377.397 & 234.3 & 50 & 41 & 210 & 11 & 29 & 20 \\
\hline Enalaprilat & 349.328 & 206.3 & 50 & 46 & 220 & 11 & 27 & 34 \\
\hline Bisoprolol & 326.435 & 116.3 & 50 & 46 & 260 & 11 & 27 & 20 \\
\hline Verapamil (IS) & 455.385 & 165.4 & 50 & 61 & 320 & 11 & 39 & 28 \\
\hline
\end{tabular}

*Abbreviations: DP, declustering potential; FP, focusing potential; EP, entrance potential; CE, collision energy; CXP, collision cell exit potential

\section{Standard solutions}

Bisoprolol, enalapril, enalaprilat and IS have weighed accurately into volumetric flasks using an analytical microbalance. Approximately 1 $\mathrm{mg} / \mathrm{ml}$ primary stock solutions of enalaprill, $0.5 \mathrm{mg} / \mathrm{ml}$ primary stock solutions of enalaprilat, $0.25 \mathrm{mg} / \mathrm{ml}$ primary stock solutions of bisoprolol and $0.5 \mathrm{mg} / \mathrm{ml}$ primary stock solutions of verapamil (IS) solutions were prepared in methanol. The stock solutions were stored at $-20^{\circ} \mathrm{C}$, which was found to be stable for $1 \mathrm{mo}$. The stock solutions of bisoprolol, enalapril, enalaprilat were successively diluted with methanol and water to prepare secondary stocks and working solutions. Secondary stock solutions and working solutions were used to prepare calibration curve (CC) and quality control (QC) samples. Working stock solutions were stored at $4{ }^{\circ} \mathrm{C}$ for a week. Working stocks were used to prepare plasma calibration standards. A working IS solution $(20 \mathrm{ng} / \mathrm{ml})$ was prepared in acetonitrile: methanol (50:50 $\mathrm{v} / \mathrm{v}$ ). Blank human plasma was screened before spiking to ensure that it was free from endogenous interference at retention times of bisoprolol, enalapril, enalaprilat and IS, respectively. Calibration standards' samples $(0.5-50 \mathrm{ng} / \mathrm{ml}$ for bisoprolol fumarate, 2-200 $\mathrm{ng} / \mathrm{ml}$ for enalapril maleate, $1-100 \mathrm{ng} / \mathrm{ml}$ for enalaprilat dehydrate) were prepared by spiking the blank human K2EDTA plasma with appropriate concentration of bisoprolol, enalapril and enalaprilat.

Samples for the determination of precision and accuracy were prepared by spiking control human plasma in bulk with bisoprolol, enalapril and enalaprilat at appropriate concentrations (for bisoprolol fumarate $1.5 \mathrm{ng} / \mathrm{ml}$ low QC [LQC], $15.0 \mathrm{ng} / \mathrm{ml}$ medium QC [MQC], and $37.5 \mathrm{ng} / \mathrm{ml}$ high QC [HQC], for enalapril maleate 6.0 $\mathrm{ng} / \mathrm{ml}$ low QC [LQC], $60.0 \mathrm{ng} / \mathrm{ml}$ medium QC [MQC], and 150.0 $\mathrm{ng} / \mathrm{ml}$ high QC [HQC], for enalaprilat dihydrate $3.0 \mathrm{ng} / \mathrm{ml}$ low QC [LQC], $30.0 \mathrm{ng} / \mathrm{ml}$ medium QC [MQC], and $75.0 \mathrm{ng} / \mathrm{ml}$ high QC [HQC],) and $120 \mu \mathrm{L}$ plasma aliquots were distributed into different tubes. All the samples were stored at $-80^{\circ} \mathrm{C} \pm 10^{\circ} \mathrm{C}$.

\section{Sample preparation}

A simple protein precipitation extraction method was followed for extraction of bisoprolol, enalapril, enalaprilat at from human plasma. 
From the deep freezer, the required quantities of CC standards and QC samples were withdrawn. The samples were thawed at room temperature. To an aliquot of $100 \mu \mathrm{l}$ plasma, $20 \mu \mathrm{l}$ of IS was added. To this mixture, $300 \mu \mathrm{l}$ of acetonitrile: methanol $(50: 50 \mathrm{v} / \mathrm{v})$ was added and vortexed for 2 min, followed by centrifugation at 6000 rpm for $5 \mathrm{~min}$ at $4{ }^{\circ} \mathrm{C}$. After centrifugation, approximately $50 \mu \mathrm{l}$ supernatant was aliquoted into, respectively, labeled autosampler vials, which were later placed in the autosampler at $15^{\circ} \mathrm{C} \pm 4{ }^{\circ} \mathrm{C} .10 \mu \mathrm{l}$ of the sample was injected onto LC-MS/MS system for analysis.

\section{Method validation}

A full validation according to the ICH guidelines [12] was performed for the assay in K2EDTA human plasma.

\section{Specificity and selectivity}

The specificity of the method was evaluated by analyzing human plasma samples from different lots to investigate the potential interferences at the chromatographic peak region for analytes and IS. The acceptance criterion for the experiment was that should have $<20 \%$ area response to that of the LLOQ level response in the same matrix. Two lots of hemolyzed plasma samples were also analyzed to ensure specificity against potential biological interferences.

\section{Linearity}

The points CC $(0.5-50 \mathrm{ng} / \mathrm{ml}$ for bisoprolol fumarate, $2-200 \mathrm{ng} / \mathrm{ml}$ for enalapril maleate, $1-100 \mathrm{ng} / \mathrm{ml}$ for enalaprilat dehydrate) were constructed by plotting the peak area ratio of each analyte: IS against the nominal concentration of calibration standards in K2EDTA human plasma. Following the evaluation of different weighing factors, the results were fit into linear regression analysis using 1/X2 (X: Concentration) weighing factor. The $\mathrm{CC}$ should have a correlation coefficient ( $r$ ) of 0.99 or better. The acceptance criteria for each backcalculated standard concentration were $\pm 15 \%$ deviation from the nominal value except at LLOQ which was set at $\pm 20 \%$.

\section{Recovery}

The efficiency of bisoprolol, enalapril,enalaprilat, and IS extraction from human plasma was determined by comparing the responses of the analytes extracted from replicate QC samples $(n=6)$ with those of neat standard solutions spiked in post-extracted plasma blank sample at equivalent concentrations by protein precipitation extraction method. Recovery of enalapril was determined at LQC $(6.28 \mathrm{ng} / \mathrm{ml})$ and HQC $(150.00 \mathrm{ng} / \mathrm{ml})$ concentrations, enalaprilat was determined at LQC $(2.99 \mathrm{ng} / \mathrm{ml})$ and $\mathrm{HQC}(75.8 \mathrm{ng} / \mathrm{ml})$ concentrations, bisoprolol was determined at LQC $(1.51 \mathrm{ng} / \mathrm{ml})$ and HQC $(36.7 \mathrm{ng} / \mathrm{ml})$ concentrations whereas the recovery of IS was determined at a single concentration of $20 \mathrm{ng} / \mathrm{ml}$.

\section{Matrix effect}

The effect of human plasma constituents over the ionization of bisoprolol, enalapril, enalaprilat, and IS was determined by postcolumn infusion method to evaluate matrix effect. Briefly, an infusion pump delivers a constant amount of analyte into LC system outlet entering to mass spectrometer inlet. To follow the analyte signal, the mass spectrometer was operated in MRM mode. The human plasma constituent sample extract was injected on LC column. A steady ion response was obtained as a function of time since the analyte was infused at a constant rate. Any endogenous compound that elutes from the column which causes a variation in ESI response of the infused analyte was seen as a suppression or enhancement in the response of the infused analyte. A separate experiment was performed with bisoprolol, enalapril, enalapril, and IS solutions, which were infused at a constant rate, and blank matrix sample injected through the LC. To evaluate matrix effect, different lots of human plasma were spiked with analyte concentration levels at LQC and HQC levels. According to guidelines, the acceptance criterion for each back-calculated concentration was $\pm 15 \%$ deviation from the nominal value.

\section{Precision and accuracy}

The intra-assay precision and accuracy were estimated by analyzing six replicates containing bisoprolol, enalapril, enalapril, at four different QC levels concentrations (for bisoprolol fumarate 1.5 $\mathrm{ng} / \mathrm{ml}$ low $\mathrm{QC}$ [LQC], $15.0 \mathrm{ng} / \mathrm{ml}$ medium QC [MQC], and $37.5 \mathrm{ng} / \mathrm{ml}$ high QC [HQC], for enalapril maleate $6.0 \mathrm{ng} / \mathrm{ml}$ low QC [LQC], 60.0 $\mathrm{ng} / \mathrm{ml}$ medium QC [MQC], and $150.0 \mathrm{ng} / \mathrm{ml}$ high QC [HQC], for enalaprilat dihydrate $3.0 \mathrm{ng} / \mathrm{ml}$ low QC [LQC], $30.0 \mathrm{ng} / \mathrm{ml}$ medium $\mathrm{QC}[\mathrm{MQC}]$, and $75.0 \mathrm{ng} / \mathrm{ml}$ high $\mathrm{QC}[\mathrm{HQC}]$ ) in human plasma. The four-level QC samples on four different runs were performed to assess the interassay precision. The acceptance criteria for each back-calculated standard concentration were $85-115 \%$ accuracy from the nominal value except at LLOQ, which was set at $80-120 \%$.

\section{Stability experiments}

Stability tests were conducted to evaluate the stability of bisoprolol, enalapril, enalaprilat in plasma samples under different conditions. $8 \mathrm{~h}$ bench top stability, processed samples stability (autosampler stability for $26 \mathrm{~h}$ at $10{ }^{\circ} \mathrm{C}$ ), three cycles of freeze-thaw stability, $30 \mathrm{~d}$ of long-term stability at $-80 \pm 10^{\circ} \mathrm{C}$ were performed at LQC and HQC levels using six replicates at each level. Samples were considered stable if assay values' acceptance criterion was of accuracy (i.e., $85-115 \%$ from fresh samples) and precision (i.e., $\pm 15 \%$ relative standard deviation [RSD]).

\section{RESULTS AND DISCUSSION}

LC separation of bisoprolol and IS has been carried out using various mobile phases consisting of different aqueous solutions and methanol or acetonitrile as the organic phase. Hernando et al. [13] used acetonitrile as an organic mobile phase to achieve shorter retention times and better resolution of bisoprolol and IS. The formic acid solution as an additive in water was used by Li et al. [14$16]$ to improve the sensitivity of MS detection.

In the present study, optimization and critical evaluation of mobile phase composition (gradient), flow rate, and analytical column were important to obtain good resolution of peaks of interest from the endogenous components, which in turn affect reproducibility and sensitivity of the method. Selection of chromatographic conditions for the proposed method was optimized to suit the preclinical pharmacokinetic studies. To ease the sample preparation in microtubes and to reduce the usage of solvent, the plasma volume was kept low. Initial feasibility experiments of a various mixture(s) of solvents such as acetonitrile, methanol and formic acid along with altered flow rates (in the range of 0.1-0.6 $\mathrm{ml} / \mathrm{min}$ ) were performed to optimize an effective chromatographic resolution of bisoprolol, enalapril, enalaprilat, and IS. Various analytical columns were tested to obtained good and reproducible response within short run time. The resolution of peaks was best achieved with Discovery C18, $50 \times$ $2.1 \mathrm{~mm}, 5 \mu \mathrm{m}$ column. Samples were chromatographed in a gradient mode (eluent A (acetonitrile-water-formic acid, 5: 95: $0.1 \mathrm{v} / \mathrm{v}$ ), eluent B (acetonitrile-formic acid, 100: $0.1 \mathrm{v} / \mathrm{v}$ )). The initial content of the eluent B is $0 \%$, which increases linearly by $1.0 \mathrm{~min}$ to $100 \%$ and to $1.01 \mathrm{~min}$ returns to the initial $0 \%$. The mobile phase was delivered at a flow rate of $0.400 \mathrm{ml} / \mathrm{min}$ into the mass spectrometer ESI chamber. The injection volume was $5 \mu \mathrm{l}$.

The purpose of sample extraction optimization is mainly to achieve high extraction recovery with negligible or low matrix effects to improve sensitivity and reliability of LC-MS/MS analysis. A poor extraction procedure decreases method robustness due to the presence of endogenous interference in the sample extracts, which are not efficiently cleaned up due to poor extraction procedure decreases the method robustness due to the endogenous interference in the sample extracts. With time-saving advantage and simplicity, the protein precipitation extraction method was chosen as an extraction method. The attained LLOQ was sufficient to quantify bisoprolol, enalapril, enalaprilat in low-dose pharmacokinetic studies.

Bisoprolol, enalapril, enalaprilat eluted at $\sim 1.01,1.03$ and $0.96 \mathrm{~min}$, respectively. During a direct infusion experiment, the mass spectra for bisoprolol, enalapril, enalaprilat and IS revealed peaks at $\mathrm{m} / \mathrm{z}$ $326.435,377.397,349.328$ and 455.385 , respectively as protonated molecular ions, $[\mathrm{M}+\mathrm{H}]+$. Typical multiple reaction monitoring chromatograms of bisoprolol, enalapril, enalaprilat and internal standard in dipotassium ethylenediaminetetraacetic acid human blank plasma are shown in fig. 4-5.

In the previous study, chromatographic separation of bisoprolol was achieved on Welchrom XB C18, $50 \times 4.6 \mathrm{~mm} 0,5 \mu \mathrm{m}$ column 
using an isocratic mobile phase $(2 \mathrm{mmol}$ ammonium formate: acetonitrile, $70: 30 \mathrm{v} / \mathrm{v}$ ) at a flow rate of $0.60 \mathrm{ml} / \mathrm{min}$. A linear response function was established at $2.04-210 \mathrm{ng} / \mathrm{ml}$ for analytes in human plasma. Total run time for this analysis was 3.5 min [6]. In the present study, total run time for analysis was less than 2.0 min.

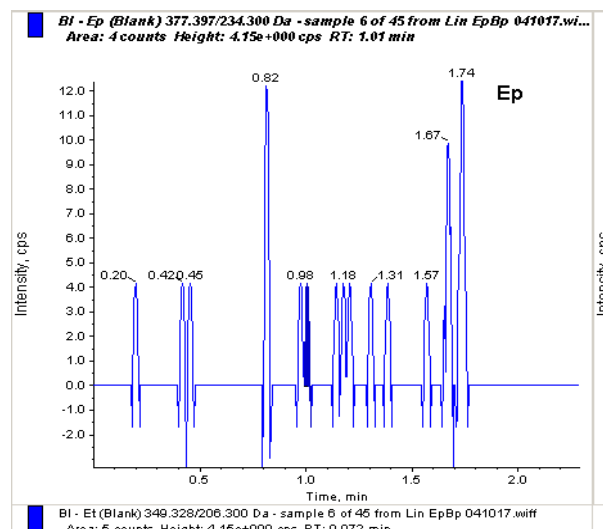

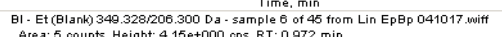

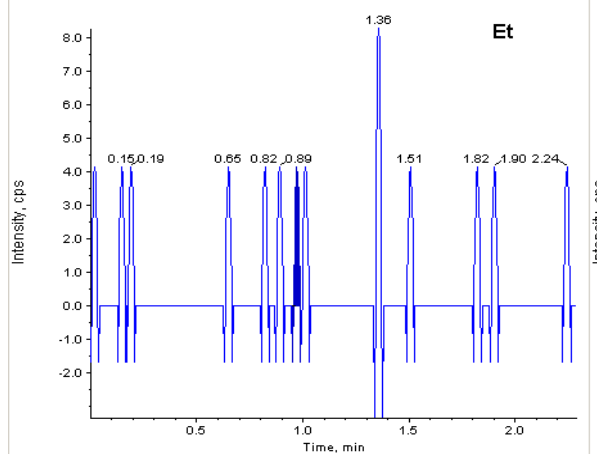

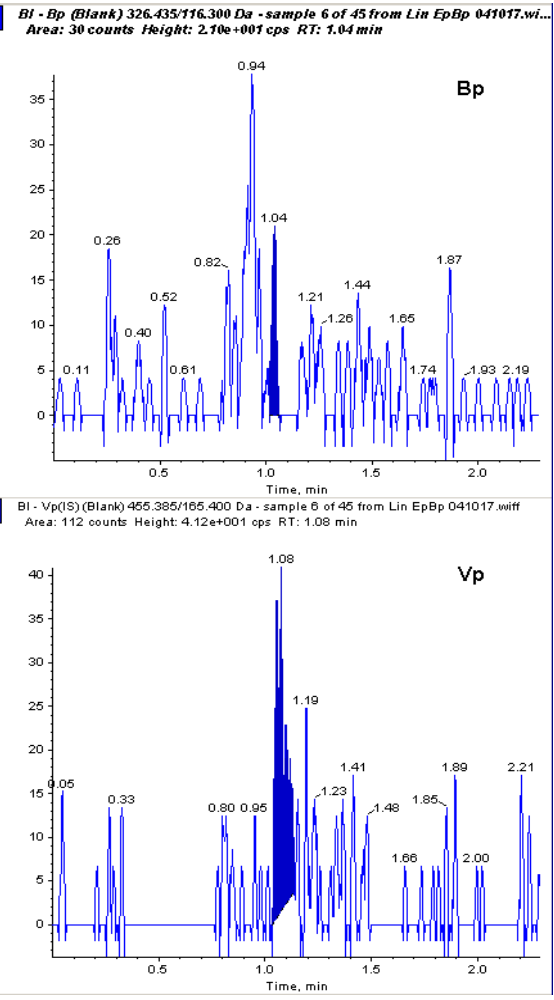

Fig. 4: Typical multiple reaction monitoring chromatograms of bisoprolol (right up panel), enalapril (left up panel), enalaprilat (left down panel) and internal standard (right down panel) in dipotassium ethylenediaminetetraacetic acid human blank plasma

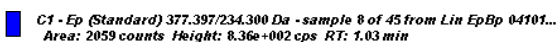

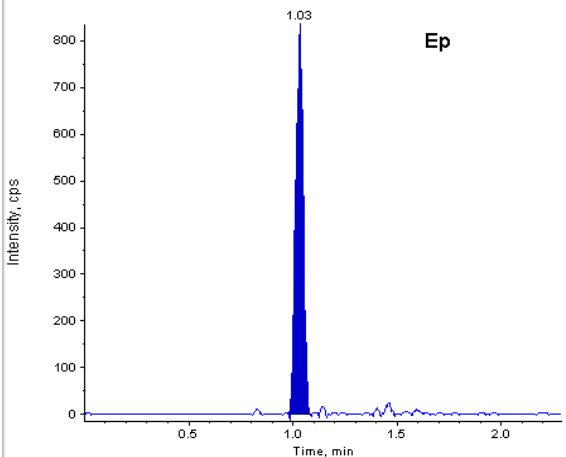

C1. Et (Standard) $349.328 / 200.300$ Da $\cdot$ Sime, minple 8 of 45 from Lin Ep Ep 041017.wiff

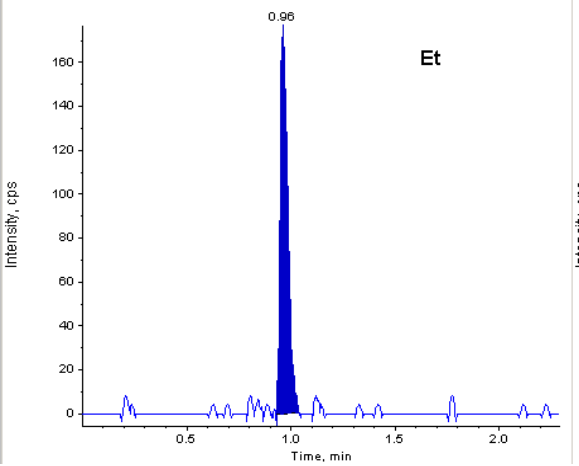

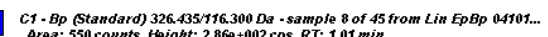

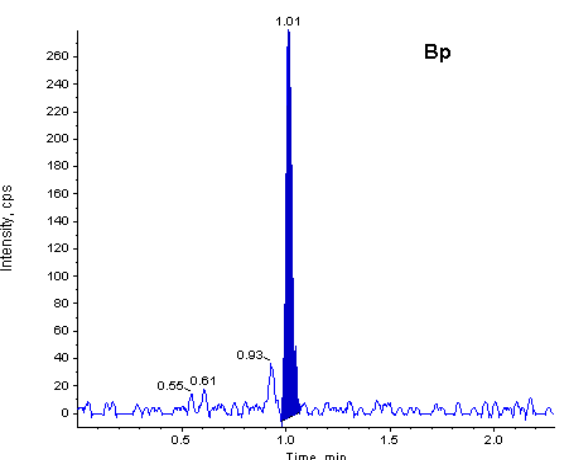

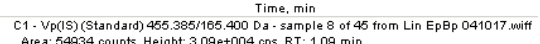

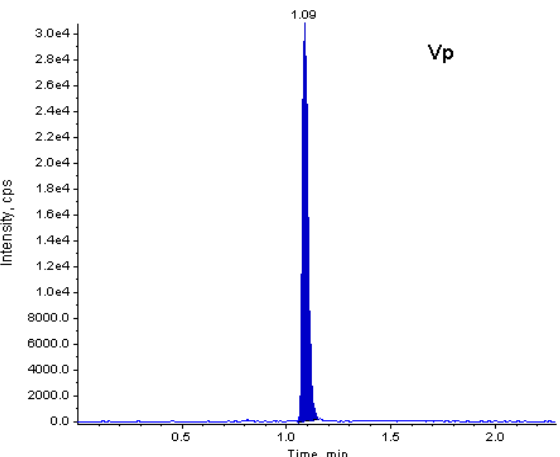

Fig. 5: Typical multiple reaction monitoring chromatograms of bisoprolol (right up panel), enalapril (left up panel), enalaprilat (left down panel) and internal standard (right down panel) in dipotassium ethylenediaminetetraacetic acid human blank plasma 
The total chromatographic run time was $2.0 \mathrm{~min}$ and the elution of bisoprolol, enalapril, enalaprilat and IS (verapamil) occurred at $\sim 1.01,1.03,0.96$ and $1.09 \mathrm{~min}$, respectively.

\section{Specificity}

Different lots of plasma were analysed to ensure that no endogenous interferences were present at the retention time of bisoprolol, enalapril, enalaprilat. LLOQ level samples along with plasma blank from the respective plasma lots were prepared and analysed (table 3 ).

\section{Linearity}

The calibration standard curves had a reliable reproducibility over the standard concentrations across the calibration range. The average regression $(n=3)$ was found to be $>0.997$ for all analytes.

Table 3: Results of specificity for bisoprolol, enalapril, enalaprilat

\begin{tabular}{|c|c|c|c|c|c|c|c|c|c|c|c|c|}
\hline \multirow[t]{3}{*}{ S. No. } & \multicolumn{4}{|c|}{ Enalapril } & \multicolumn{4}{|c|}{ Enalaprilat } & \multicolumn{4}{|c|}{ Bisoprolol } \\
\hline & \multirow[t]{2}{*}{ STD BL } & \multicolumn{2}{|l|}{ LLOQ } & \multirow[t]{2}{*}{$\%$ interference } & \multirow[t]{2}{*}{ STD BL } & \multicolumn{2}{|l|}{ LLOQ } & \multirow[t]{2}{*}{$\%$ interference } & \multirow[t]{2}{*}{ STD BL } & \multicolumn{2}{|l|}{ LLOQ } & \multirow[t]{2}{*}{$\%$ interference } \\
\hline & & Area & RT & & & Area & RT & & & Area & RT & \\
\hline 1 & 0 & 2190 & 1.03 & NIL & 0 & 394 & 0.97 & NIL & 0 & 557 & 1.01 & NIL \\
\hline 2 & 0 & 2208 & 1.03 & NIL & 0 & 420 & 0.96 & NIL & 0 & 563 & 1.01 & NIL \\
\hline 3 & 0 & 2098 & 1.03 & NIL & 0 & 394 & 0.97 & NIL & 0 & 570 & 1.01 & NIL \\
\hline 4 & 0 & 2190 & 1.03 & NIL & 0 & 394 & 0.97 & NIL & 0 & 557 & 1.01 & NIL \\
\hline 5 & 0 & 2190 & 1.03 & NIL & 0 & 503 & 0.96 & NIL & 0 & 554 & 1.01 & NIL \\
\hline 6 & 0 & 2208 & 1.04 & NIL & 0 & 379 & 0.98 & NIL & 0 & 558 & 1.01 & NIL \\
\hline 7 & 0 & 2098 & 1.03 & NIL & 0 & 382 & 0.96 & NIL & 0 & 551 & 1.01 & NIL \\
\hline 8 & 0 & 2126 & 1.03 & NIL & 0 & 379 & 0.97 & NIL & 0 & 547 & 1.01 & NIL \\
\hline 9 & 0 & 2190 & 1.03 & NIL & 0 & 501 & 0.97 & NIL & 0 & 543 & 1.01 & NIL \\
\hline 10 & 0 & 2224 & 1.03 & NIL & 0 & 420 & 0.97 & NIL & 0 & 547 & 1.01 & NIL \\
\hline
\end{tabular}

*Average of triplicate injections, In all plasma blanks, the response at the retention time of bisoprolol, enalapril, enalaprilat was less than $20 \%$ of LLOQ response and at the retention time of IS, the response was less than $5 \%$ of mean IS response in LLOQ.

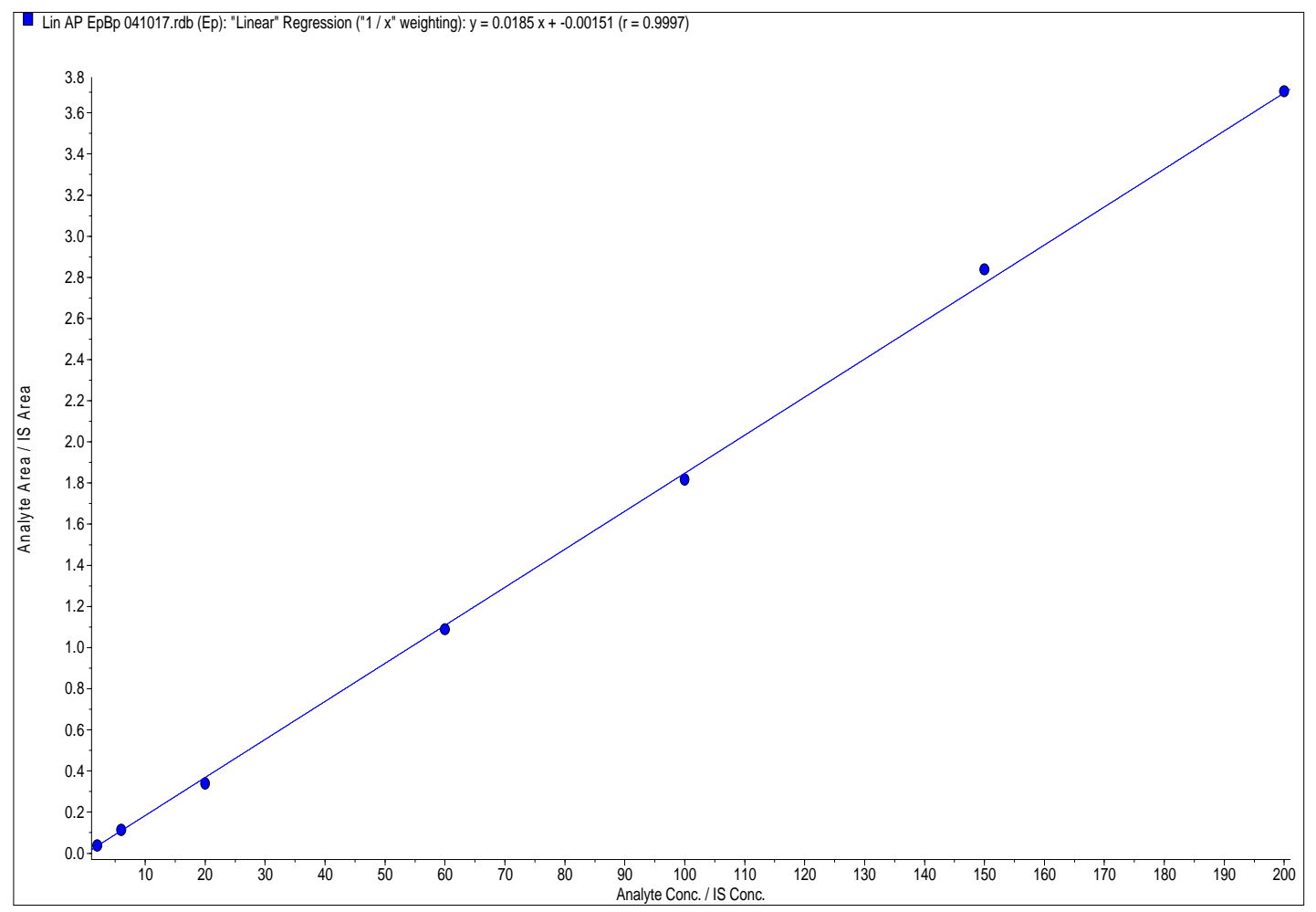

Fig. 6: The calibration curve of enalapril maleate in human plasma

The calibration curve (fig. 6) (peak area ratio Vs Concentration) was linear over working range for enalapril maleate of 2 to $200.00 \mathrm{ng} / \mathrm{ml}$ with 7 point calibration used for quantification by linear regression, shown in fig. 6 . The regression equation for the analysis was

$Y=0.0185 x+0.00151$ with coefficient of correction $(r 2)=0.9997$.

The calibration curve (fig. 7) (peak area ratio Vs Concentration) was linear over working range for enalaprilat dihydrate of 1 to $100.00 \mathrm{ng} / \mathrm{ml}$ with 7 point calibration used for quantification by linear regression, shown in fig. 7 . The regression equation for the analysis was
$\mathrm{Y}=0.00732 \mathrm{x}+0.000198$ with coefficient of correction (r2) $=0.9998$.

The calibration curve (fig. 8) (peak area ratio Vs Concentration) was linear over working range for bisoprolol fumarate of 0.5 to 50.00 $\mathrm{ng} / \mathrm{ml}$ with 7 point calibration used for quantification by linear regression, shown in fig. 8 . The regression equation for the analysis was

$Y=0.0195 x+0.000763$ with coefficient of correction $(r 2)=0.9997$.

In the previous study, a linear response function was established at 2.04-210 ng/ml for bisoprolol in human plasma. [6]. In the present 
study, a linear response function was established at $0.5-50 \mathrm{ng} / \mathrm{ml}$ for bisoprolol fumarate, $2-200 \mathrm{ng} / \mathrm{ml}$ for enalapril maleate, $1-100 \mathrm{ng} / \mathrm{ml}$

for enalaprilat dehydrate in human plasma.

\section{Recovery}

The \% mean recovery for bisoprolol, enalapril, enalaprilat in LQC, MQC and HQC are listed in tables 4-6.

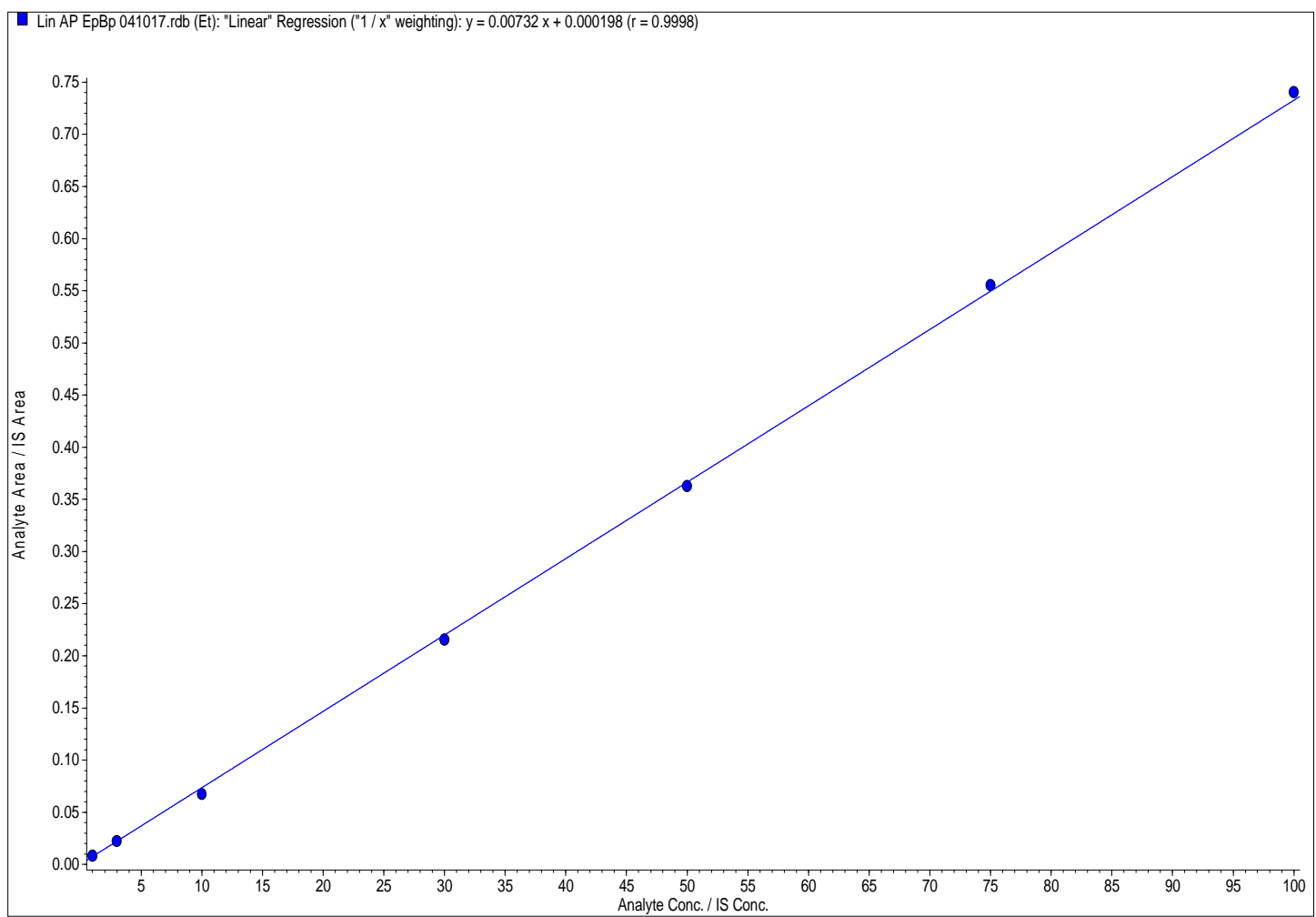

Fig. 7: The calibration curve of enalaprilat dihydrate in human plasma

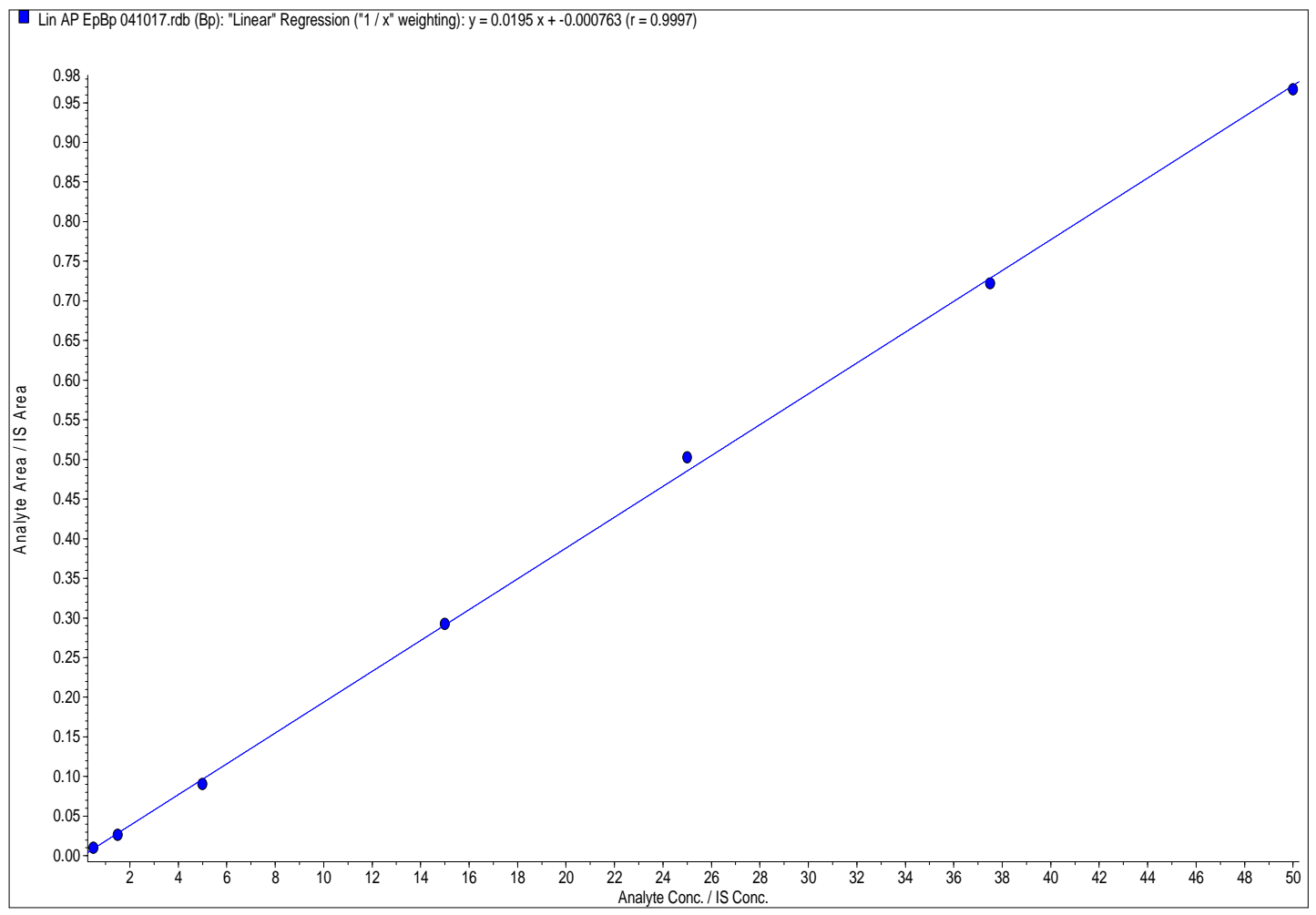

Fig. 8: The calibration curve of bisoprolol fumarate in human plasma 
Table 4: The \% mean recovery of enalapril for LQC, MQC and HQC

\begin{tabular}{|c|c|c|c|}
\hline S. No. & LQC & MQC & HQC \\
\hline 1 & 6.03 & 62.9 & 154 \\
\hline 2 & 6.37 & 58.8 & 142 \\
\hline 3 & 5.86 & 58.9 & 144 \\
\hline 4 & 6.91 & 63.3 & 153 \\
\hline 5 & 6.22 & 60.6 & 159 \\
\hline Mean & 6.28 & 60.9 & 150 \\
\hline SD & 0.402 & 2.14 & 7.16 \\
\hline$\% \mathrm{CV}$ & 6.4 & 3.5 & 4.8 \\
\hline$\%$ Mean Recovery & 104.6 & 101.5 & 100.3 \\
\hline
\end{tabular}

*Abbreviations: Lower quality control (LQC), middle-quality control (MQC), higher quality control (HQC), Each value is represented as a mean \pm SD of 5 observations ( $n=5)$, SD: Standard Deviation, RSD: Relative Standard Deviation, \#Acceptance criteria<2.0.

Table 5: The \% mean recovery of enalaprilat for LQC, MQC and HQC

\begin{tabular}{|c|c|c|c|}
\hline S. No. & LQC & MQC & HQC \\
\hline 1 & 3.00 & 31.2 & 78.6 \\
\hline 2 & 2.89 & 27.6 & 73.9 \\
\hline 3 & 3.04 & 28.4 & 73.4 \\
\hline 4 & 3.09 & 30.7 & 76.2 \\
\hline 5 & 2.93 & 31.3 & 77.1 \\
\hline Mean & 2.99 & 29.8 & 75.8 \\
\hline SD & 0.081 & 1.72 & 2.18 \\
\hline$\% \mathrm{CV}$ & 2.7 & 5.8 & 2.9 \\
\hline \% Mean Recovery & 99.7 & 99.4 & 101.1 \\
\hline
\end{tabular}

*Abbreviations: Lower quality control (LQC), middle-quality control (MQC), higher quality control (HQC), Each value is represented as a mean \pm SD of 5 observations ( $n=5$ ), SD: Standard Deviation, RSD: Relative Standard Deviation, \#Acceptance criteria<2.0.

Table 6: The \% mean recovery of bisoprolol for LQC, MQC and HQC

\begin{tabular}{|c|c|c|c|}
\hline S. No. & LQC & MQC & HQC \\
\hline 1 & 1.51 & 15.1 & 37.3 \\
\hline 2 & 1.57 & 15.9 & 34.6 \\
\hline 3 & 1.46 & 14.8 & 35.6 \\
\hline 4 & 1.42 & 15.6 & 36.9 \\
\hline 5 & 1.57 & 15.3 & 39.1 \\
\hline Mean & 1.51 & 15.3 & 36.7 \\
\hline SD & 0.067 & 0.43 & 1.72 \\
\hline$\% \mathrm{CV}$ & 4.4 & 2.8 & 4.7 \\
\hline \% Mean Recovery & 100.4 & 102.3 & 97.9 \\
\hline
\end{tabular}

*Abbreviations: Lower quality control (LQC), middle-quality control (MQC), higher quality control (HQC), Each value is represented as a mean \pm SD of 5 observations ( $n=5$ ), SD: Standard Deviation, RSD: Relative Standard Deviation, \#Acceptance criteria<2.0.

The \% mean recovery for enalapril in LQC, MQC and HQC was 104.6 $\%, 101.5 \%$ and $100.3 \%$, for enalaprilat in LQC, MQC and HQC was $99.7 \%, 99.4 \%$ and $101.1 \%$, for bisoprolol in LQC, MQC and HQC was $100.4 \%, 102.3 \%$ and $97.9 \%$ respectively.

\section{Intraday (within run) and Inter-day (between run) precision} and accuracy

The within-run coefficients of variation ranged between $0.311 \%$ and $0.647 \%$ for bisoprolol. The within-run percentages of nominal concentrations ranged between $99.82 \%$ and $100.82 \%$ for bisoprolol. The between-run coefficients of variation ranged between $0.364 \%$ and $0.572 \%$ for bisoprolol. The between-run percentages of nominal concentrations ranged between $99.27 \%$ and $100.76 \%$ for bisoprolol. Results are presented in table 7. The assay values on both the occasions (intra-and inter-day) were found to be within the accepted limits.

The within-run coefficients of variation ranged between $0.321 \%$ and $0.747 \%$ for enalapril. The within-run percentages of nominal concentrations ranged between $99.93 \%$ and $101.31 \%$ for enalapril. The between-run coefficients of variation ranged between $0.390 \%$ and $0.673 \%$ for enalapril. The between-run percentages of nominal concentrations ranged between $99.47 \%$ and $102.76 \%$ for enalapril. Results are presented in table 8.

Table 7: Intra-day and Inter-day precision data of bisoprolol

\begin{tabular}{llll}
\hline Day & Intra-day precision & & Inter-day precision \\
\cline { 2 - 4 } & Mean & R. S. D. \% & Mean \\
\hline 1 & 99.82 & 0.311 & 100.76 \\
2 & 100.41 & 0.647 & 99.27 \\
3 & 100.82 & 0.336 & 100.53 \\
\hline
\end{tabular}

*Each value is represented as a mean \pm SD of observations, SD: Standard Deviation, RSD: Relative Standard Deviation, \#Acceptance criteria $<2.0$ 
Table 8: Intra-day and Inter-day precision data of enalapril

\begin{tabular}{lllll}
\hline Day & Intra-day precision & & Inter-day precision \\
\cline { 2 - 5 } & Mean & R. S. D. \% & Mean & R. S. D. \% \\
\hline 1 & 99.93 & 0.321 & 102.76 & 0.564 \\
2 & 101.31 & 0.747 & 99.47 & 0.390 \\
3 & 100.82 & 0.376 & 100.13 & 0.673 \\
\hline
\end{tabular}

*Each value is represented as a mean \pm SD of observations, SD: Standard Deviation, RSD: Relative Standard Deviation, \#Acceptance criteria<2.0

Table 9: Intra-day and Inter-day precision data of enalaprilat

\begin{tabular}{llll}
\hline Day & Intra-day precision & & Inter-day precision \\
\cline { 2 - 4 } & Mean & R. S. D. \% & Mean \\
\hline 1 & 99.13 & 0.221 & 100.16 \\
2 & 100.31 & 0.547 & 99.87 \\
3 & 100.62 & 0.336 & 101.33 \\
\hline
\end{tabular}

*Each value is represented as a mean \pm SD of observations, SD: Standard Deviation, RSD: Relative Standard Deviation, \#Acceptance criteria<2.0

The within-run coefficients of variation ranged between $0.221 \%$ and $0.547 \%$ for enalaprilat. The within-run percentages of nominal concentrations ranged between $99.13 \%$ and $100.62 \%$ for enalaprilat. The between-run coefficients of variation ranged between $0.264 \%$ and $0.773 \%$ for enalaprilat. The between-run percentages of nominal concentrations ranged between $99.87 \%$ and $101.33 \%$ for enalaprilat. Results are presented in table 9.

In the previous study, the intraday and interday accuracy and precisions were in the range of $1.12-7.87 \%$ and $1.26-6.36 \%$ and $1.46-6.13 \%$ and $1.65-7.34 \%$ for bisoprolol and triamterene, respectively [6]. In the present study, the intraday and interday accuracy and precisions were in the range of $0.311 \%-0.647 \%$ and $0.364 \%-0.572 \%$ for bisoprolol, $0.321 \%-0.747 \%$ and $0.390 \%-$ $0.673 \%$ for enalapril, $0.221 \%-0.547 \%$ and $0.264 \%-0.773 \%$ for enalaprilat, respectively. The assay values the occasions (intra-and inter-day) were found to be within the accepted limits.

\section{Matrix effect}

The lowest concentration with the $\mathrm{RSD}<20 \%$ was taken as LLOQ and was found to be $2.19 \mathrm{ng} / \mathrm{ml}$ for enalapril, $1.01 \mathrm{ng} / \mathrm{ml}$ for enalaprilat, $0.585 \mathrm{ng} / \mathrm{ml}$ for bisoprolol.

The \% accuracy of LLOQ samples prepared with the different biological matrix lots was found $109.5 \%$ for enalapril, $101.1 \%$ for enalaprilat, $117.1 \%$ for bisoprolol, which were found within the range of $80.00-120.00 \%$ for the seven different plasma lots. $\% \mathrm{CV}$ for LLOQ samples was observed as 3.1\%, $12.0 \%, 7.0 \%$ respectively, which are within $20.00 \%$ of the acceptance criteria. Results are presented in tables 10-12.

Table 10: Results of matrix effect of enalapril

\begin{tabular}{ll}
\hline S. No. & LLQC \\
\hline 1 & 2.18 \\
2 & 2.17 \\
3 & 2.14 \\
4 & 2.31 \\
5 & 2.16 \\
Mean & 2.19 \\
SD & 0.068 \\
$\%$ CV & 3.1 \\
\% Mean recovery & 109.5 \\
\hline
\end{tabular}

* Abbreviations: Lower limit of quantification (LLOQ), Each value is represented as a mean \pm SD of 5 observations (n=5), SD: Standard Deviation, RSD: Relative Standard Deviation, \#Acceptance criteria $<2.0$.

Table 11: Results of matrix effect of enalaprilat

\begin{tabular}{ll}
\hline S. No. & LLQC \\
\hline 1 & 0.924 \\
2 & 0.973 \\
3 & 1.22 \\
4 & 0.93 \\
5 & 1.01 \\
Mean & 1.01 \\
SD & 0.122 \\
$\%$ CV & 12.0 \\
$\%$ Mean recovery & 101.1 \\
\hline
\end{tabular}

* Abbreviations: Lower limit of quantification (LLOQ), Each value is represented as a mean \pm SD of 5 observations ( $n=5$ ), SD: Standard Deviation, RSD: Relative Standard Deviation, \#Acceptance criteria $<2.0$.

\section{Stability}

The predicted concentrations for bisoprolol $(1.51 \mathrm{ng} / \mathrm{ml}$ and 36.7 $\mathrm{ng} / \mathrm{ml})$, enalapril $(6.28 \mathrm{ng} / \mathrm{ml}$ and $150.0 \mathrm{ng} / \mathrm{ml})$, enalaprilat $(2.99$ $\mathrm{ng} / \mathrm{ml}$ and $75.8 \mathrm{ng} / \mathrm{ml}$ ) deviated within $\pm 15 \%$ of the fresh sample concentrations in a battery of stability tests namely, in-injector $(22$ h), bench-top $(7 \mathrm{~h})$, and repeated four freeze/thaw cycles stability (table 13). 
Table 12: Results of matrix effect of bisoprolol

\begin{tabular}{lc}
\hline S. No. & LLQC \\
\hline 1 & 0.547 \\
2 & 0.581 \\
3 & 0.655 \\
4 & 0.571 \\
5 & 0.572 \\
Mean & 0.585 \\
SD & 0.041 \\
\% Mean recovery & 7.0 \\
\hline
\end{tabular}

* Abbreviations: Lower limit of quantification (LLOQ), Each value is represented as a mean \pm SD of 5 observations (n=5), SD: Standard Deviation, RSD: Relative Standard Deviation, \#Acceptance criteria $<2.0$.

Table 13: Stability data of bisoprolol, enalapril, enalapril at QCs in human plasma

\begin{tabular}{|c|c|c|c|c|}
\hline \multirow[t]{2}{*}{ Nominal concentration $(\mathrm{ng} / \mathrm{ml})$} & \multirow[t]{2}{*}{ Stability } & \multicolumn{3}{|l|}{ Stability data } \\
\hline & & mean $\pm S D^{\circ}(n=6)$ & Accuracy (\%)• & Precision (\% CV) \\
\hline \multirow{4}{*}{ Bisoprolol-1.51 } & $0 \mathrm{~h}$ & $1.50 \pm 0.32$ & 99.3 & 2.29 \\
\hline & $7 \mathrm{~h}$ (bench-Top) & $1.50 \pm 0.42$ & 99.3 & 2.36 \\
\hline & $22 \mathrm{~h}$ (in-injector) & $1.50 \pm 0.52$ & 99.3 & 2.60 \\
\hline & 3 FT cycles & $1.49 \pm 0.42$ & 99.3 & 2.30 \\
\hline \multirow[t]{4}{*}{ Enalapril-6.28 } & $0 \mathrm{~h}$ & $6.27 \pm 0.37$ & 99.8 & 3.01 \\
\hline & $7 \mathrm{~h}$ (bench-Top) & $6.27 \pm 0.22$ & 99.8 & 2.71 \\
\hline & $22 \mathrm{~h}$ (in-injector) & $6.26 \pm 0.42$ & 99.6 & 3.36 \\
\hline & 3 FT cycles & $6.26 \pm 0.37$ & 99.6 & 2.96 \\
\hline \multirow[t]{4}{*}{ Enalaprilat-2.99 } & $0 \mathrm{~h}$ & $2.98 \pm 0.38$ & 99.6 & 3.05 \\
\hline & $7 \mathrm{~h}$ (bench-Top) & $2.98 \pm 0.45$ & 99.6 & 3.12 \\
\hline & $22 \mathrm{~h}$ (in-injector) & $2.97 \pm 0.67$ & 99.3 & 3.43 \\
\hline & 3 FT cycles & $2.96 \pm 0.44$ & 98.9 & 3.11 \\
\hline \multirow[t]{4}{*}{ Bisoprolol-36.7 } & $0 \mathrm{~h}$ & $36.6 \pm 0.37$ & 99.7 & 2.07 \\
\hline & $7 \mathrm{~h}$ (bench-Top) & $36.6 \pm 0.63$ & 99.7 & 3.34 \\
\hline & $22 \mathrm{~h}$ (in-injector) & $36.5 \pm 0.32$ & 99.4 & 2.32 \\
\hline & 3 FT cycles & $36.5 \pm 0.57$ & 99.4 & 3.01 \\
\hline \multirow[t]{4}{*}{ Enalapril-150.0 } & $0 \mathrm{~h}$ & $149.9 \pm 0.51$ & 99.9 & 3.15 \\
\hline & $7 \mathrm{~h}$ (bench-Top) & $149.7 \pm 0.31$ & 99.8 & 2.32 \\
\hline & $22 \mathrm{~h}$ (in-injector) & $149.6 \pm 0.22$ & 99.7 & 2.02 \\
\hline & 3 FT cycles & $149.2 \pm 0.64$ & 99.4 & 3.24 \\
\hline \multirow[t]{4}{*}{ Enalaprilat-75.8 } & $0 \mathrm{~h}$ & $75.5 \pm 0.53$ & 99.6 & 3.08 \\
\hline & $7 \mathrm{~h}$ (bench-Top) & $75.3 \pm 0.27$ & 99.3 & 2.04 \\
\hline & $22 \mathrm{~h}$ (in-injector) & $75.3 \pm 0.38$ & 99.3 & 2.54 \\
\hline & 3 FT cycles & $75.1 \pm 0.57$ & 99.0 & 2.84 \\
\hline
\end{tabular}

${ }^{\circ}$ Back-calculated plasma concentrations; •Mean assayed concentration/mean assayed concentration at $0 \mathrm{~h} \times 100$. FT: Freeze-thaw, SD: Standard deviation, QC: Quality control, The results were found to be within the assay variability limits during the entire process.

\section{CONCLUSION}

In summary, a highly sensitive, specific, reproducible, rapid and high-throughput LC-MS/MS assay was developed and validated to quantify bisoprolol and enalapril in the present of enalaprilat in human plasma as per the regulatory guidelines. The present method involved a simple precipitation method of sample preparation, which gave consistent and reproducible recoveries. The sample volume requirement supports the possibility to study the full pharmacokinetic profile in individuals. Furthermore, the rationale for selecting the combination of bisoprolol and enalapril is justifiable. Hence, the combination was taken up for developing a bioanalytical method development and validation so that further it would be useful for performing pharmacokinetic studies.

\section{CONFLICTS OF INTERESTS}

Declared none

\section{REFERENCES}

1. Yuliya Kondratova, Liliya Logoyda, Yuliia Voloshko, Ahmed Abdel-Megied, Dmytro Korobko, Yuriy Soroka. Development and validation of HPLC-DAD method for the determination of bisoprolol in tablet dosage forms. Int J Appl Pharm 2017;9:54-9.

2. Liliya Logoyda, Dmytro Korobko, Iryna Ivanusa, Kovalenko Serhii. Development of the methodology of the chromatographic determination of nifedipine in medicines. Asian J Pharm Clin Res 2017;10:149-52.

3. Dinga L, Zhoua X, Guoa X, Songa Q, He J, Xub G. LC-ESI-MS method for the determination of bisoprolol in human plasma. J Pharm Biomed Anal 2007;44:520-5.

4. Bhatt J, Subbaiah G, Kambli S, Shah B, Patel M, Saxena A, et al. A high throughput and sensitive liquid chromatography-tandem mass spectrometry (LC-MS/MS) method for the estimation of bisoprolol in human plasma using multiplexing technique. J Chromatogr B 2007;852:374-81.

5. Liu GY, Wang W, Jia JY, Lu C, Liu YM, Zhang MQ, et al. Liquid chromatography-tandem mass spectrometry method for determination of bisoprolol in human plasma using d5-bisoprolol as the internal standard. Biomed Chromatogr 2010;24:574-80.

6. Hemavathi G, Hipparagi SM. Sensitive liquid chromatographytandem mass spectrometric method for the simultaneous determination of bisoprolol and triamterene in human plasma. Asian J Pharm Clin Res 2017;10:341-8.

7. Yang XM, Wang CB. Determination of bisoprolol in urine by fluorometry. Fenxi Shiyanshi Chin 2001;20:54-5.

8. Braza AJ, Modamio P, Lastra CF, Mariño EL. Development, validation and analytical error function of two chromatographic methods with fluorimetric detection for the determination of bisoprolol and metoprolol in human plasma. Biomed Chromatogr 2002;16:517-22. 
9. Agapova NN, Vasileva E. HPLC method for determination of bisoprolol and potential impurities. J Chromatogr A 1993;654:299-302.

10. Kintz P, Lohner S, Tracqui A, Mangin P, Lugnier A, Chaumont AJ. Rapid HPLC determination of bisoprolol in human plasma. J Anal Chem 1990;336:517-9.

11. Buehring KU, Garbe A. Determination of the new beta-blocker bisoprolol and of metoprolol, atenolol and propranolol in plasma and urine by high-performance liquid chromatography. J Chromatogr Biomed Appl 1986;55:215-24.

12. Harmonised Tripartite Guideline: Validation of Analytical Procedures: Methodology (Q2B) 2005. International Conference on Harmonisation (ICH); 2005.

13. Hernando MD, Petrovic M, Fernandez-Alba AR, Barcelo D. Analysis by liquid chromatography-electrospray ionization tandem mass spectrometry and acute toxicity evaluation for beta-blockers and lipid-regulating agents in wastewater samples. J Chromatogr A 2004;1046:133-40.

14. Li S, Liu G, Jia J, Liu Y, Pan C, Yu C, et al. Simultaneous determination of ten antiarrhythmics drugs and a metabolite in human plasma by liquid chromatography-tandem mass spectrometry. J Chromatogr B Anal Technol Biomed Life Sci 2007;847:174-81

15. Darshan Bhatt, B Rajkamal. A UPLC-MS/MS method development and validation for the estimation of sofosbuvir from human plasma. Int J Appl Pharm 2017;9:30-6.

16. Delma D'cruz, Anu Babu, Eena Joshy, Aneesh TP. Bioanalytical method development and validation of ticagrelor by RP-HPLC. Int J Appl Pharm 2017;9:51-4. 